\title{
Evaluation of the bioequivalence and food effect on the bioavailability of CC-486 (oral azacitidine) tablets in adult patients with cancer
}

\author{
Hani M. Babiker ${ }^{1}\left(\mathbb{D} \cdot\right.$ Mohammed Milhem $^{2} \cdot$ Joseph Aisner $^{3} \cdot$ William Edenfield $^{4} \cdot$ Dale Shepard $^{5} \cdot$ Michael Savona $^{6}$. \\ Swaminathan Iyer ${ }^{7} \cdot$ Maen Abdelrahim $^{8} \cdot$ C. L. Beach ${ }^{9} \cdot$ Barry Skikne $^{9,10} \cdot$ Eric Laille $^{9} \cdot$ Kao-Tai Tsai $^{9} \cdot$ Thai Ho $^{11}$
}

Received: 28 September 2019 / Accepted: 22 January 2020 / Published online: 8 February 2020

(c) The Author(s) 2020

\begin{abstract}
Purpose CC-486 is an oral formulation of azacitidine that allows for extended dosing schedules to prolong azacitidine exposure to malignant cells and maximize clinical activity. CC-486 $300 \mathrm{mg}$ daily, administered for 14 or 21 days of 28-day treatment cycles, is currently under investigation in two ongoing phase III trials. The 300-mg daily dose in these studies is administered as two 150-mg tablets (Formulation A).

Methods We evaluated the bioequivalence of one 300-mg CC-486 tablet (Formulation B) with Formulation A and food effect on Formulation B, in adult patients with cancer in a 2-stage crossover design study.

Results The ratios of the geometric means of the maximum azacitidine plasma concentration $\left(C_{\max }\right)$ and of the area under the plasma concentration-time curve from time 0 extrapolated to infinity $\left(\mathrm{AUC}_{\infty}\right)$ were $101.5 \%$ and $105.7 \%$, demonstrating the bioequivalence of Formulations A and B. Formulation B was rapidly absorbed under fasted and fed conditions. The geometric mean of $C_{\max }$ was significantly decreased by $\sim 21 \%$ in the fed state. Median $T_{\max }$ was reached at $2 \mathrm{~h}$ and $1 \mathrm{~h}$ post-dose in fed and fasted states, respectively $(P<0.001)$. Nevertheless, systemic drug exposure (AUC) in fed and fasted states was within the $80-125 \%$ boundaries of bioequivalence and differences in $C_{\max }$ and $T_{\max }$ are not expected to have a clinical impact. Conclusion The single 300-mg CC-486 tablet was bioequivalent to two $150-\mathrm{mg}$ tablets, which have shown to be efficacious and generally well-tolerated in clinical trials, and can be taken with or without food.
\end{abstract}

Keywords Oral azacitidine $\cdot$ CC-486 $\cdot$ Pharmacokinetics $\cdot$ Bioequivalence

Electronic supplementary material The online version of this article (https://doi.org/10.1007/s00280-020-04037-9) contains supplementary material, which is available to authorized users.

Hani M. Babiker

hanibabiker@email.arizona.edu

1 University of Arizona Comprehensive Cancer Center, Tucson, AZ, USA

2 University of Iowa Hospital, Iowa City, IA, USA

3 Rutgers Cancer Institute of New Jersey, New Brunswick, NJ, USA

4 Greenville Health System, Greenville, SC, USA

5 Cleveland Clinic, Cleveland, OH, USA

6 Vanderbilt University Medical Center, Nashville, TN, USA

7 MD Anderson Cancer Center, Houston, TX, USA

8 Houston Methodist Hospital, Houston, TX, USA

9 Celgene Corporation, Summit, NJ, USA

10 University of Kansas Medical Center, Kansas City, KS, USA

11 Mayo Clinic, Phoenix, AZ, USA

\section{Introduction}

Azacitidine is a cytidine nucleoside analog and DNA methyltransferase inhibitor (DNMTi) used in the treatment of patients with various malignancies. Injectable azacitidine $75 \mathrm{mg} / \mathrm{m}^{2} /$ day, administered intravenously (IV) or subcutaneously (SC) for 7 days per 28-day treatment cycle, is approved in several countries for treatment of myelodysplastic syndromes (MDS) and acute myeloid leukemia (AML) $[1,2]$. Azacitidine has also been investigated in a variety of other hematologic malignancies and solid tumors [3-6]. In addition to direct cytotoxicity of proliferating malignant cells, azacitidine is incorporated into both RNA and DNA (in human AML KG1a cells, the RNA:DNA incorporation ratio was 65:35 [7]) and reduces hypermethylation in promoter regions of DNA, leading to re-expression of tumor suppressor genes and promoting differentiation of hematopoietic progenitor cells [7-9]. Azacitidine has a short plasma half-life, and DNA incorporation of azacitidine is 
S-phase restricted [10]. DNA hypomethylation is highest during the first half of each injectable azacitidine treatment cycle, but returns to baseline levels by the end of the cycle [11].

CC-486 is an oral formulation of azacitidine that allows for extended dosing schedules to prolong azacitidine exposure and thus maximize hypomethylating effects $[12,13]$. Early clinical studies showed CC-486 to be bioavailable, well-tolerated, and clinically active in patients with MDS, AML, or chronic myelomonocytic leukemia (CMML) [11, $12,14]$. When administered for 7 days per treatment cycle, global DNA hypomethylation with CC-486 was less extensive than with 7-day administration of SC azacitidine [11], but extended CC-486 dosing schedules-taken for 14 or 21 days per cycle-were associated with sustained hypomethylation through the end of the treatment cycle $[12,13]$.

CC-486 administere in extended dosing schedules is currently under investigation in ongoing clinical studies, including two large, randomized phase III trials, as maintenance therapy for patients with AML in first remission after induction chemotherapy (NCT01757535), and as front-line treatment for patients with lower-risk MDS with concurrent thrombocytopenia and RBC transfusion dependence (NCT01566695). In the AML and MDS phase III trials, CC-486 $300 \mathrm{mg}$ is administered once-daily (as two 150-mg immediate-release tablets) for 14 or 21 days, respectively, of 28-day cycles.

Studies have shown higher adherence and decreased healthcare resource utilization with single-tablet medication regimens compared with regimens that require multiple pills $[15,16]$. Thus, a new formulation of CC-486 was developed that allows for CC-486 to be administered as one 300-mg tablet. This formulation, as a single tablet, would be preferable for use by patients.

We conducted a two-stage, phase I study in adult patients with cancer to evaluate the bioequivalence of the new single 300-mg tablet with that of the two 150-mg tablets used in the two phase III trials. This tablet has different excipients and a different ratio of active pharmaceutical ingredient (API) to excipients compared with the 150-mg tablet. Additionally, because food restrictions can alter PK characteristics, we determined the food effect on the bioavailability of the 300-mg tablet.

\section{Materials and methods}

This phase I, open-label, multicenter, randomized, crossover study was conducted in accordance with Good Clinical Practice, and adhered to the International Conference on Harmonization Guideline E6 and ethical principles outlined in the Declaration of Helsinki. The study received approval from relevant independent review boards or ethics committees (listed in the Supplementary Appendix) before commencement. All patients provided written informed consent. This study is registered at ClinicalTrials.gov (NCT01519011).

\section{Patients}

Eligible patients were age $\geq 18$ years with hematologic malignancies or solid tumors and Eastern Cooperative Oncology Group (ECOG) performance status scores $\leq 2$, who were relapsed or proved refractory to prior therapy, or for whom no standard treatments were available. Patients with gastrointestinal tumors or tumors that originated or metastasized to the liver were excluded.

\section{Study design}

The trial comprised two stages:

Stage 1 evaluated the relative bioequivalence of the pharmacokinetic (PK) parameters two formulations of CC-486. Patients were randomized 1:1 to receive one dose of CC-486 either as two 150-mg tablets (Formulation A) or a single 300-mg tablet (Formulation B) in a fasted state on day 1, and then crossed over to receive one dose of the alternate CC-486 dosing regimen (also in a fasted state) after an interval of $\geq 48 \mathrm{~h}$ following the initial dose.

Stage 2 assessed the food effect on the bioavailability of CC-486 Formulation B. Patients were randomized 1:1 to receive the single CC-486 300-mg tablet on each of two PK study days under fed or fasted conditions, and then crossed over to receive the same 300-mg tablet formulation under the opposite (fasted or fed) condition after an interval of $\geq 48 \mathrm{~h}$.

Fasted state required an overnight fast of at least $8 \mathrm{~h}$, and no food was allowed for at least $2 \mathrm{~h}$ post-dose. Water could be taken as desired, except for $1 \mathrm{~h}$ before or after CC-486 administration. In the fed state, following an overnight fast, patients were to eat breakfast $30( \pm 5)$ min before planned administration of CC-486. A high-fat ( $50 \%$ of total caloric content) and high-calorie $(\sim 800-1000 \mathrm{cal})$ breakfast was consumed, comprising approximately 150 , 250 , and 500-600 cal from protein, carbohydrate, and fat, respectively.

Blood samples for $\mathrm{PK}$ assessments were collected before administration of CC-486, and at $0.25,0.5,1,1.5,2,2.5,3$, $3.5,4,6$, and $8 \mathrm{~h}$ post-dose. All plasma PK samples were analyzed centrally using a validated proprietary high-performance liquid chromatography/tandem mass spectrometric method. The lower limit of quantitation for azacitidine in human plasma was $1.00 \mathrm{ng} / \mathrm{mL}$, with linearity demonstrable to $1000 \mathrm{ng} / \mathrm{mL}$ (upper limit of quantitation). PK parameters evaluated were area under the plasma concentration-time curve from time 0 to time $t$ (time to last measurable concentration $\left.\left[\mathrm{AUC}_{t}\right]\right)$ and from time 0 extrapolated to infinity $\left(\mathrm{AUC}_{\infty}\right)$, maximum plasma concentration $\left(C_{\max }\right)$, time to 
$C_{\max }\left(T_{\max }\right)$, terminal half-life $\left(t_{1 / 2}\right)$, apparent total clearance $(\mathrm{CL} / F)$ and volume of distribution $(\mathrm{Vz} / F)$.

After completing Stage 1 or Stage 2, patients could enter an extension phase of the study and receive azacitidine $75 \mathrm{mg} / \mathrm{m}^{2} /$ day IV or SC for 7 consecutive days of repeated 28-day cycles for up to six cycles.

\section{Statistical analyses}

We chose a sample size of 54 patients in each stage (approximately 60 patients enrolled to account for $\sim 10 \%$ dropout rate) to provide $90 \%$ power to conclude bioequivalence and food effect, respectively, assuming the within-patient coefficient of variation as approximately $30 \%$. Power calculations are based on a two one-sided test procedure at the 5\% significance level for bioequivalence acceptance limits (80, 125 ) and assumes a true mean ratio of the log-transformed PK parameters $\mathrm{AUC}_{\infty}$ and $C_{\max }$ between 0.95 and 1.05 when comparing the test $(1 \times 300 \mathrm{mg}$ tablet $)$ and reference $(2 \times 150 \mathrm{mg}$ tablet $)$ in the bioequivalence stage; and the test $(1 \times 300 \mathrm{mg}$ tablet under fasted condition) and reference $(1 \times 300 \mathrm{mg}$ tablet under fed condition) in the food effect stage. For $T_{\text {max }}$, a non-parametric statistical method was used to compare the median $T_{\max }$ between formulations A and B, and between fed vs fasted states.

\section{Results}

\section{Bioequivalence (Stage 1)}

Although planned to enroll 54 patients, preliminary analysis of data from the first 30 patients enrolled in Stage 1 demonstrated bioequivalence between the two formulations. Among these patients, median age was 68.5 years (range 46-86). Three patients (10\%) had hematologic malignancies and 27 (90\%) had solid tumors (Supplementary Table 1). Most patients were white (90\%), male (67\%), and had previously received anticancer or immunomodulatory agents (90\%).

CC-486 was rapidly absorbed following administration of a single 300-mg oral dose. Mean plasma concentration-time profiles were well characterized over the sampling interval and were below the level of detection from the $6 \mathrm{~h}$ post-dose timepoint (Fig. 1a). For Formulation A and Formulation B, mean $C_{\max }$ values were 143.0 and $145.1 \mathrm{ng} / \mathrm{mL}$, respectively, and mean $\mathrm{AUC}_{\infty}$ values were 228.5 and $241.6 \mathrm{ng} * \mathrm{~h} / \mathrm{mL}$. The mean $t_{1 / 2}$ was 0.544 and $0.492 \mathrm{~h}$, mean CL/F was 1313 and $1242 \mathrm{~L} / \mathrm{h}$, and mean $\mathrm{Vz} / F$ was 1031 and $881.1 \mathrm{~L}$ for Formulation A and Formulation B, respectively. For both formulations, a median $T_{\max }$ of $1.0 \mathrm{~h}$ was observed with no statistically significant difference $(P<0.710)$ (Supplementary Table 2). The ratio of the geometric means of $C_{\max }$ was
$101.5 \%$ (90\% CI 89.9, 114.7) and of total drug exposure $\left(\mathrm{AUC}_{\infty}\right)$ was $105.7 \%(95.0,117.6)$, indicating Formulation B is bioequivalent to Formulation A (Supplementary Table 2).

\section{Food effect (Stage 2)}

A total of 59 patients were enrolled in the food effect portion of this study. Two patients discontinued before receiving study drug, so 57 patients were used to determine the effect of food on the bioavailability of CC-486 Formulation B. Median age was 62 years (range 31-88). All 57 patients had solid tumors (Supplementary Table 1). As in Stage 1, most patients were white (93.0\%), male (59.6\%), and had received prior anticancer or immunomodulatory agents (94.7\%).

Following administration of a single oral dose of $300 \mathrm{mg}$ under fasted and fed conditions, CC-486 was rapidly absorbed and mean plasma concentration-time profiles were well characterized over the sampling interval and were below the level of detection between 6 and 8-h post-dose sampling time points (Fig. 1b). Under fasted and fed condition, respectively, mean $C_{\max }$ was 131.7 and $105.2 \mathrm{ng} / \mathrm{mL}$, mean $\mathrm{AUC}_{\infty}$ was 234.5 and $248.9 \mathrm{ng} * \mathrm{~h} / \mathrm{mL}$, mean $t_{1 / 2}$ was 0.58 and $0.78 \mathrm{~h}$, mean $\mathrm{CL} / F$ was 1280 and $1205 \mathrm{~L} / \mathrm{h}$, and mean $\mathrm{Vz} / F$ was 1074 and $1279 \mathrm{~L}$ (Table 1).

The $90 \% \mathrm{CI}$ of the ratio of the geometric means for $C_{\max }$ (68.6-90.7\%) did not include $100 \%$, indicating that there was a statistically significant difference for $C_{\max }$ (Table 1), with a fed/fasted ratio of the geometric means of approximately $79 \%$. Moderate intra-patient variability was noted for $C_{\max }$ $(\mathrm{CV} \%=45.5 \%)$. Consistent with an effect of food on gastric emptying, median $T_{\max }$ was reached at $2 \mathrm{~h}$ and $1 \mathrm{~h}$ postdose in fed and fasted states, respectively $(P<0.001)$ (Table 1$)$.

Despite differences in $C_{\max }$ and $T_{\max }$, overall drug exposure $\left(\mathrm{AUC}_{\infty}\right)$ in fasted and fed states was similar: the fed/ fasted ratio of the geometric means was $108.9 \%$ and the $90 \%$ $\mathrm{CI}$ of the ratios of the geometric means for $\mathrm{AUC}_{\infty}(90 \% \mathrm{CI}$ $98.5,120.5)$ were within the $80-125 \%$ bioequivalence limits (Table 1). CL/F and $\mathrm{Vz} / F$ were also comparable in fed and fasted states. Again, moderate to high interpatient variability was observed for all CC-486 PK parameters.

\section{Discussion}

Oral antineoplastic agents are a primary form of treatment in many malignancies. When efficacy and safety are not compromised, oral agents are generally preferred to parenteral treatments [17]. Compared with parenteral therapy, oral anticancer agents allow convenient dosing outside of the clinic [17]. However, adherence is required to ensure therapeutic efficacy and to avoid compromising treatment outcomes, especially in cases of symptomatic or rapidly progressing disease, where dose-intensity is important [18]. Indeed, 
Fig. 1 a Bioequivalence: arithmetic mean $( \pm$ SE) CC-486 plasma concentration-time profiles for two CC-486 formulations (Formulation A, $2 \times 150 \mathrm{mg}$; Formulation B, $1 \times 300 \mathrm{mg}$ ). b Food effect: arithmetic mean $( \pm$ SE) CC-486 plasma concentrations with one 300-mg tablet (Formulation B) in fasted and fed states
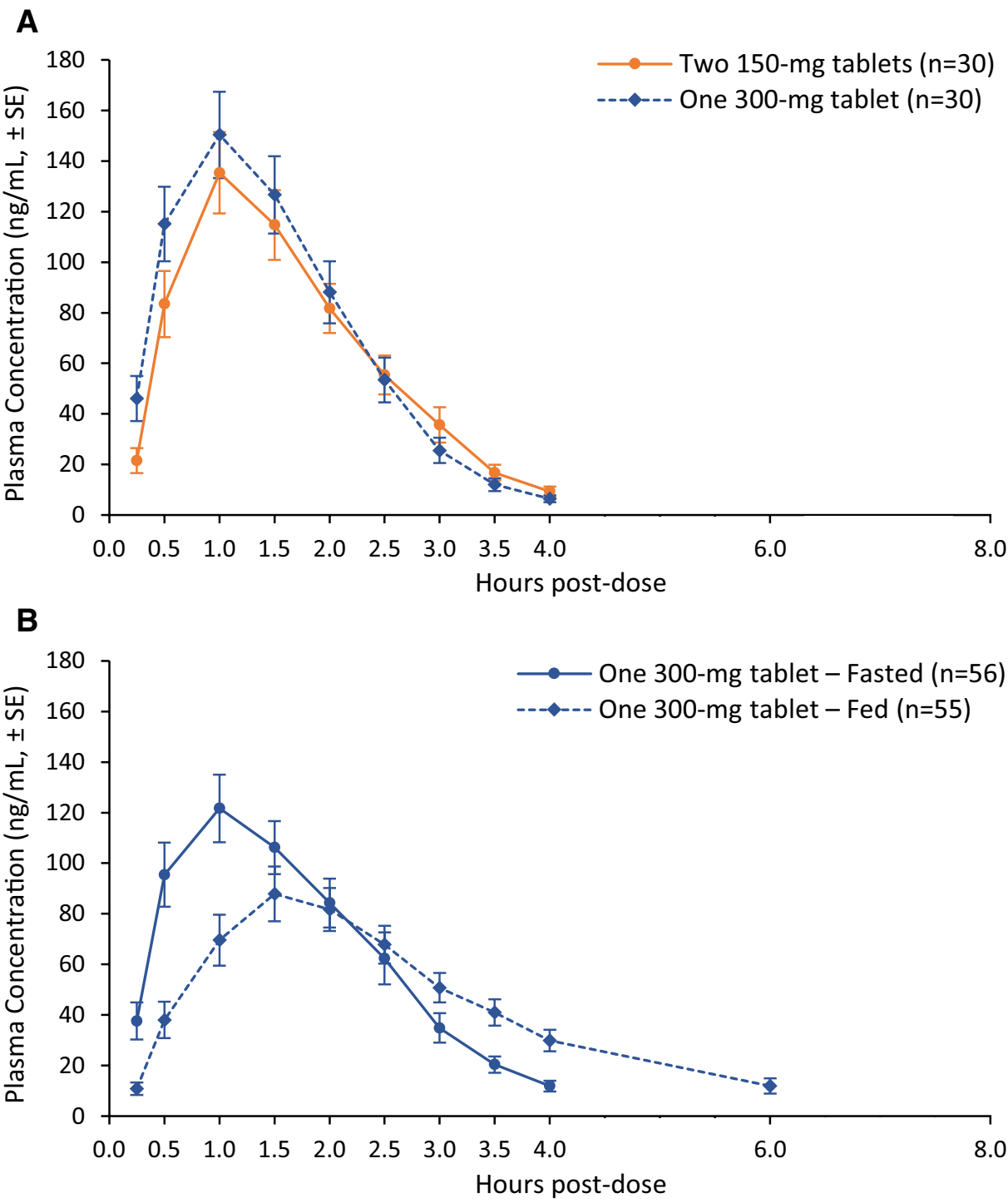

suboptimal adherence may be the greatest barrier to effective use of oral anticancer agents [19]. Studies show statistically significant correlations between medication nonadherence and clinical and resource utilization outcomes, including cancer progression, prolonged inpatient durations, higher total healthcare spending, and poorer survival [20].

The simplicity of the anticancer regimen may influence adherence to treatment. Many patients with cancer are older and may have multiple comorbidities for which they take multiple medications. The number of anticancer pills and frequency of administration can add to the medication burden that patients experience [21] and adherence rates tend to be higher when simpler, once-daily regimens are combined with lower pill burden [16]. This study showed that a single oral CC-486 Formulation B 300-mg tablet was bioequivalent to two Formulation A 150-mg tablets. CC-486 is intended for once-daily dosing. Theoretically, a single tablet prohibits dose splitting, increasing the likelihood that patients receive the correct dose of the prescribed medication.

A lack of food restrictions may also enhance adherence to drug therapy. In this study, food was shown to have no clinically relevant effect on PK parameters of the 300-mg tablet compared with a fasted condition. Although $C_{\max }$ occurred later and was decreased by $\sim 21 \%$ after a high-fat meal compared with the fasted state, systemic drug exposure (AUC) in fed and fasted states was within the bounds of bioequivalence (80-125\%). Thus, observed differences in $C_{\max }$ and $T_{\max }$ between fed and fasted states would not be expected to have a clinical impact. These results are generally consistent with outcomes of an early PK study of Formulation A (two 150-mg tablets) that showed no effect of food on $\mathrm{PK}$ parameters $\left(C_{\max }\right.$ and $\left.\mathrm{AUC}_{\infty}\right)$ compared with the fasted state [22]. Unlike the earlier study, however, the current study evaluated food effect on a single 300-mg tablet after a high-fat meal (per FDA guidance), 
Table 1 Food effect on the plasma pharmacokinetic parameters of the CC-486 $300 \mathrm{mg}$ Formulation B tablet

\begin{tabular}{|c|c|c|c|c|c|c|c|c|c|c|}
\hline Condition & \multicolumn{2}{|c|}{ Statistic } & \multicolumn{2}{|c|}{$\mathrm{AUC}_{t}(\mathrm{ng} * \mathrm{~h} / \mathrm{mL})$} & $\operatorname{AUC}_{\infty}(\mathrm{ng} * \mathrm{~h} / \mathrm{mL})$ & $C_{\max }(\mathrm{ng} / \mathrm{mL})$ & $T_{\max }(\mathrm{h})$ & $t_{1 / 2}(\mathrm{~h})$ & $\mathrm{CL} / F(\mathrm{~L} / \mathrm{h})$ & $\mathrm{Vz} / F(\mathrm{~L})$ \\
\hline \multirow[t]{5}{*}{ Fasted } & \multicolumn{2}{|l|}{$N$} & \multicolumn{2}{|l|}{56} & 54 & 56 & 56 & 54 & 54 & 54 \\
\hline & \multicolumn{2}{|c|}{ Geometric mean* } & \multicolumn{2}{|l|}{224.9} & 234.5 & 131.7 & NA & 0.58 & 1280 & 1074 \\
\hline & \multicolumn{2}{|c|}{ Geometric \% CV } & \multicolumn{2}{|l|}{68.4} & 62.9 & 70.4 & NA & 31.6 & 62.9 & 76.2 \\
\hline & \multicolumn{2}{|c|}{ Median } & \multicolumn{2}{|l|}{240} & 243 & 141 & 1.0 & 0.55 & 1230 & 1140 \\
\hline & \multicolumn{2}{|c|}{ Min, $\max$} & \multicolumn{2}{|c|}{$41.5,1050$} & $65.9,1050$ & $21.4,608$ & $0.50,4.0$ & $0.35,1.7$ & 286,4550 & 228,6310 \\
\hline \multirow[t]{5}{*}{ Fed } & \multicolumn{2}{|l|}{$N$} & \multicolumn{2}{|l|}{55} & 44 & 55 & 55 & 46 & 44 & 44 \\
\hline & \multicolumn{2}{|c|}{ Geometric mean* } & \multicolumn{2}{|l|}{233.7} & 248.9 & 105.2 & NA & 0.78 & 1205 & 1279 \\
\hline & Geor & etric \%CV & 58.3 & & 52.0 & 76.3 & NA & 55.2 & 52.0 & 80.5 \\
\hline & Med & & 250 & & 250 & 116 & 2.0 & 0.68 & 1200 & 1160 \\
\hline & Min, & $\operatorname{nax}$ & 61.3, & & $78.9,560$ & $22.7,337$ & $0.50,6.1$ & $0.40,6.2$ & 536,3800 & 399,9350 \\
\hline PK parame & & Condi & & $N$ & Geometric mean ${ }^{\dagger}$ & $\begin{array}{l}\text { Ratio (\%) } \\
\text { ric mean }\end{array}$ & of geomet- & $\begin{array}{l}90 \% \mathrm{CI} \text { of } \\
\text { geometric }\end{array}$ & $\begin{array}{l}\text { atio }(\%) \text { of } \\
\text { heans }\end{array}$ & $\begin{array}{l}\text { Intra- } \\
\text { patient } \\
\% \mathrm{CV}\end{array}$ \\
\hline $\mathrm{AUC}_{t}(\mathrm{ng} *$ & (mL) & Fasted & & 56 & 227.8 & 101.7 & & $(92.83,11$ & & 29.0 \\
\hline & & Fed & & 55 & 231.8 & & & & & \\
\hline $\mathrm{AUC}_{\infty}(\mathrm{ng}$ & $1 / \mathrm{mL})$ & Fasted & & 56 & 133.0 & 108.9 & & $(98.48,12$ & & 28.3 \\
\hline & & Fed & & 55 & 104.9 & & & & & \\
\hline$C_{\max }(\mathrm{ng} / \mathrm{m}$ & & Fasted & & 56 & 133.0 & 78.86 & & $(68.58,90$ & & 45.5 \\
\hline & & Fed & & 55 & 104.9 & & & & & \\
\hline PK parame & & Condition & $N$ & Median & Median diffe & $90 \%$ & I of mediar & difference & ed-fasted) & $P$ value \\
\hline$T_{\max }(\mathrm{h})^{\ddagger}$ & & Fasted & 56 & 1.0 & 1.0 & $(0.7$ & 1.3) & & & $<0.001$ \\
\hline & & Fed & 55 & 2.0 & & & & & & \\
\hline
\end{tabular}

$\mathrm{AUC}_{\infty}, t_{1 / 2}, \mathrm{CL} / F$, and $V / F$ could not be calculated in some instances, if there were not data from a sufficient number of time points after the occurrence of $C_{\max }$. Slight differences in geometric means of $\mathrm{AUC}_{\infty}$ and $C_{\max }$ are due to different methods of calculation

$N$ patients the total number of patients for which the PK parameter could be calculated, $A U C_{t}$ area under the plasma concentration-time curve from time 0 to time $t, A U C_{\infty}$ area under the plasma concentration-time curve from time 0 extrapolated to infinity, $C_{\max }$ maximum plasma concentration, $T_{\max }$ time to $C_{\max }, t_{1 / 2}$ terminal half-life, $C L / F$ apparent total clearance, $V z / F$ volume of distribution, $N A$ not applicable

*Calculated using summary statistics

$\dagger$ Calculated using an analysis of variance (ANOVA) model

${ }^{*}$ Median and median difference (test vs. reference), and $90 \%$ CI of the median difference, are from Hodges-Lehmann estimate. The $P$ value is from Wilcoxon signed-rank test.

and was statistically powered to make more definitive PK comparisons with the fasted state.

The single 300-mg CC-486 Formulation B tablet was found to be bioequivalent to two 150-mg Formulation A tablets, that have been shown efficacious and generally well-tolerated in clinical trials [14], and the 300-mg CC-486 tablet can be taken with or without food. The single-tablet formulation will be more convenient for patients and will be used for registration purposes to support further development of CC-486 for use in various malignancies.

Acknowledgements This study was funded by Celgene Corporation. Editorial support was provided by Sheila Truten and Brian Kaiser (Medical Communication Company, Inc; Wynnewood, PA), funded by Celgene Corporation. The authors were fully responsible for all content and editorial decisions for this paper.

\section{Compliance with ethical standards}

Conflict of interest HMB: Consultancy: Endocyte, Celgene, Tracon, Guradant360; Honoraria: Bayer, SirTex. MM: Advisory board and consultancy: Blueprint Medicines, Immunocore, Amgen, Trieza, Array Biopharma, BionTech. WE: Consultancy and stock ownership: Inteliquet. DS: Advisory board: Sanofi, Genzyme; Consultancy: Harpoon Therapeutics; Research funding: Nectar, Celgene, Amgen, Pfizer, BMS, Leap, Corvus; Speaker's bureau: Celgene, Genetech. MS: Advisory board: Celgene; Consultancy: Celgene, Abbvie, Astex, Karyopharm; Research support: Astex, Incyte, Sunesis, Takada, TG Therapeutics; Stock ownership: Karyopharm. SI: Research support: Celgene. JA, MA: Nothing to disclose. CLB, BS, EL, and KTT: Employment and stock ownership: Celgene. TH: Advisory board and honorarium: Genentech, Cardinal Health, Pfizer, Surface Oncology, Exelixis, Ipsen; Research funding: Novartis.

Ethical approval This phase I, open-label, multicenter, randomized, crossover study was conducted in accordance with Good Clinical Practice, and adheres to the International Conference on Harmoniza- 
tion Guideline E6 and ethical principles outlined in the Declaration of Helsinki. The study received approval from relevant independent review boards or ethics committees before commencement. All patients provided written informed consent. This study is registered at ClinicalTrials.gov (NCT01519011).

Open Access This article is licensed under a Creative Commons Attribution 4.0 International License, which permits use, sharing, adaptation, distribution and reproduction in any medium or format, as long as you give appropriate credit to the original author(s) and the source, provide a link to the Creative Commons licence, and indicate if changes were made. The images or other third party material in this article are included in the article's Creative Commons licence, unless indicated otherwise in a credit line to the material. If material is not included in the article's Creative Commons licence and your intended use is not permitted by statutory regulation or exceeds the permitted use, you will need to obtain permission directly from the copyright holder. To view a copy of this licence, visit http://creativecommons.org/licenses/by/4.0/.

\section{References}

1. Vidaza ${ }^{\circledR}$ (azacitidine) prescribing information (2018) Celgene Corporation, Summit, NJ; Revision 9/2018

2. European Medicines Agency (2016) Vidaza (azacitidine). EMA/450923/452016

3. AL Cohen A Ray M Brocklin Van DM Burnett RC Bowen DL Dyess TW Butler T Dumlao HT Khong 2017 A phase I trial of azacitidine and nanoparticle albumin bound paclitaxel in patients with advanced or metastatic solid tumors Oncotarget 83252413 52419 https://doi.org/10.18632/oncotarget.14183

4. C Nervi E Marinis De G Codacci-Pisanelli 2015 Epigenetic treatment of solid tumours: a review of clinical trials Clin Epigenetics 7127 https://doi.org/10.1186/s13148-015-0157-2

5. YM Abaza TM Kadia EJ Jabbour MY Konopleva G Borthakur A Ferrajoli Z Estrov WG Wierda A Alfonso TH Chong C Chuah LP Koh BC Goh JE Chang DE Durkes MC Foudray HM Kantarjian XQ Dong G Garcia-Manero 2017 Phase 1 dose escalation multicenter trial of pracinostat alone and in combination with azacitidine in patients with advanced hematologic malignancies Cancer 1232448514859 https://doi.org/10.1002/cncr.30949

6. Y Nieto BC Valdez PF Thall RB Jones W Wei A Myers C Hosing S Ahmed U Popat EJ Shpall M Qazilbash A Gulbis P Anderlini N Shah Q Bashir A Alousi Y Oki M Fanale B Dabaja C Pinnix R Champlin BS Andersson 2016 Double epigenetic modulation of high-dose chemotherapy with azacitidine and vorinostat for patients with refractory or poor-risk relapsed lymphoma Cancer 1221726802688 https://doi.org/10.1002/cncr.30100

7. PW Hollenbach AN Nguyen H Brady M Williams Y Ning N Richard L Krushel SL Aukerman C Heise KJ MacBeth 2010 A comparison of azacitidine and decitabine activities in acute myeloid leukemia cell lines PLoS ONE 52 e9001 https://doi.org/10.1371/ journal.pone.0009001

8. LH Li EJ Olin TJ Fraser BK Bhuyan 1970 Phase specificity of 5-azacytidine against mammalian cells in tissue culture Cancer Res 301127702775

9. LH Li EJ Olin HH Buskirk LM Reineke 1970 Cytotoxicity and mode of action of 5-azacytidine on L1210 leukemia Cancer Res 301127602769

10. JK Christman N Mendelsohn D Herzog N Schneiderman 1983 Effect of 5-azacytidine on differentiation and DNA methylation in human promyelocytic leukemia cells (HL-60) Cancer Res 432 763769

11. G Garcia-Manero SD Gore C Cogle R Ward T Shi KJ Macbeth E Laille H Giordano S Sakoian E Jabbour H Kantarjian B Skikne 2011 Phase I study of oral azacitidine in myelodysplastic syndromes, chronic myelomonocytic leukemia, and acute myeloid leukemia J Clin Oncol 291825212527 https://doi.org/10.1200/ JCO.2010.34.4226

12. G Garcia-Manero SD Gore S Kambhampati B Scott A Tefferi CR Cogle WJ Edenfield J Hetzer K Kumar E Laille T Shi KJ MacBeth B Skikne 2016 Efficacy and safety of extended dosing schedules of CC-486 (oral azacitidine) in patients with lower-risk myelodysplastic syndromes Leukemia 304889896 https://doi. org/10.1038/leu.2015.265

13. E Laille T Shi G Garcia-Manero CR Cogle SD Gore J Hetzer K Kumar B Skikne KJ MacBeth 2015 Pharmacokinetics and pharmacodynamics with extended dosing of CC-486 in patients with hematologic malignancies PLoS ONE 108 e0135520 https://doi. org/10.1371/journal.pone.0135520

14. MR Savona K Kolibaba P Conkling EC Kingsley C Becerra JC Morris RM Rifkin E Laille A Kellerman SM Ukrainskyj Q Dong BS Skikne 2018 Extended dosing with CC-486 (oral azacitidine) in patients with myeloid malignancies Am J Hematol 93101199 1206 https://doi.org/10.1002/ajh.25216

15. SS Sutton JW Hardin TJ Bramley AO D'Souza CL Bennett 2016 Single- versus multiple-tablet HIV regimens: adherence and hospitalization risks Am J Manag Care 224242248

16. PG Clay S Nag CM Graham S Narayanan 2015 Meta-analysis of studies comparing single and multi-tablet fixed dose combination HIV treatment regimens Medicine (Baltimore) 9442 e1677 https ://doi.org/10.1097/MD.0000000000001677

17. D Eek M Krohe I Mazar A Horsfield F Pompilus R Friebe AL Shields 2016 Patient-reported preferences for oral versus intravenous administration for the treatment of cancer: a review of the literature Patient Prefer Adherence 1016091621 https://doi. org/10.2147/PPA.S106629

18. AR Mislang TM Wildes R Kanesvaran C Baldini HM Holmes G Nightingale A Coolbrandt L Biganzoli 2017 Adherence to oral cancer therapy in older adults: the International Society of Geriatric Oncology (SIOG) taskforce recommendations Cancer Treat Rev 575866 https://doi.org/10.1016/j.ctrv.2017.05.002

19. AH Partridge J Avorn PS Wang EP Winer 2002 Adherence to therapy with oral antineoplastic agents J Natl Cancer Inst 949 $652661 \mathrm{https}: / /$ doi.org/10.1093/jnci/94.9.652

20. JA Greer N Amoyal L Nisotel JN Fishbein J MacDonald J Stagl I Lennes JS Temel SA Safren WF Pirl 2016 A systematic review of adherence to oral antineoplastic therapies Oncologist 213354 $376 \mathrm{https}: / /$ doi.org/10.1634/theoncologist.2015-0405

21. BA Given CW Given A Sikorskii E Vachon A Banik 2017 Medication burden of treatment using oral cancer medications Asia Pac J Oncol Nurs 44275282 https://doi.org/10.4103/apjon.apjon 7_17

22. E Laille MR Savona BL Scott TE Boyd Q Dong B Skikne 2014 Pharmacokinetics of different formulations of oral azacitidine (CC-486) and the effect of food and modified gastric $\mathrm{pH}$ on pharmacokinetics in subjects with hematologic malignancies J Clin Pharmacol 546630639 https://doi.org/10.1002/jcph.251

Publisher's Note Springer Nature remains neutral with regard to jurisdictional claims in published maps and institutional affiliations. 